\title{
СРАВНЕНИЕ КОЛИЧЕСТВА ПРОСМОТРОВ ПОЛЬЗОВАТЕЛЬСКИХ ОТЗЫВОВ В БАНКОВСКОМ СЕКТОРЕ
}

\section{(c) 2021 Плотников Андрей Викторович}

кандидат экономических наук, доцент, доцент кафедры менеджмента и маркетинга Пермский национальный исследовательский политехнический университет, Россия, Пермь

E-mail:plotnikov-av@mail.ru

ORCID: https://orcid.org/0000-0001-5777-3969

\section{(C) 2021 Урасова Анна Александровна}

кандидат экономических наук, доцент, доцент кафедры государственного и муниципального управления

Пермский государственный национальный исследовательский университет, Россия, Пермь

E-mail: annaalexandrowna@mail.ru

https://orcid.org/0000-0002-0598-5051

В работе рассматриваются цели пользовательских отзывов, их предназначение. На выбор потребителя влияют отзывы/комментарии других потребителей, уже столкнувшихся с объектом, после взаимодействия с которым происходит рефлексия, воплощаемая в отзыве. Осознание последовательности «покупка - опыт - рефлексия» помогает организациям улучшать свой сервис и продвигать товары/услуги на рынке. Задача отзывов заключается в формировании знаний у потенциального покупателя в условиях неопределенности информации или ее неоднозначности. В качестве данных для эмпирической части послужили отзывы пользователей с сайта banki.ru o Сбербанке в количестве $(\mathrm{N}=82051)$. С целью проверки гипотезы о том, что негативные отзывы чаще читаются (или позитивные читаются реже), были проанализированы показатели «просмотры» и «оценка» отзывов. Результаты исследования частично подтверждают гипотезу. Частичность подтвержденной гипотезы означает то, что к положительным отзывам мы отнесли отзывы с оценкой «4» И «5», а как мы видим из результатов исследования, только отзывы с оценкой «5» статистически отличаются в меньшую сторону от всех остальных отзывов.

Ключевые слова: отзывы, онлайн-коммуникации, управление репутацией, интернет-маркетинг.

\section{Введение}

Актуальность исследования заключается в том, что в начале XXI в. с увеличением количества персональных компьютеров и большему распространению сети интернет, появились новые возможности для анализа общественного мнения, индивидуальных предпочтений потребителей (пользователей). С распространением концепции Web 2.0 (развитие блогосферы и социальных сетей, двусторонних рынков) выросла креативная составляющая пользователей Интернета, которая отодвинула на второй план роли профессиональных критиков, т.к. эти роли примерили на себя рядовые пользователи. Притом, что анонимность пользователя повлияла на откровенность и раскованность, что дало рост авторской самореализации в тексте. Исходя из этого, результаты труда пользователей в концепции Web 2.0 обеспечивают рост интереса к объекту исследования со стороны ученых и практиков [2]. В качестве объекта может выступать продукт/услуга, подобъекты, относящиеся к объекту. В нашем исследовании с точки зрения мониторинга объектом выступают банковские продукты, а с точки зрения анализа - отзывы пользователей с сайта banki.ru.

\section{Теоретическая часть}

Рассмотрим несколько определений интернет-отзыва. И.В.Погорелова рассматривает интернет-отзыв как размещённое в сети асинхронное речевое произведение, содержание которого составляет мнение автора о продукте или услуге [7]. Е.Э.Былина предлагает обобщенное понятие на основе анализа литературы: «интернет-отзыв - это речевое произведение, относящееся к классу речевых жанров наивного дискурса, реализуемое в рамках асинхронной виртуальной коммуникации и содержащее в себе мнение и оценку автора о товаре 
или услуге.» [3] Рекомендательные отзывы выполняют две функции: первая - отслеживание количества пользователей, которым понравился или не понравился отзыв на основании количества «лайков» (позитивных реакцией), а вторая функция: стимулирование других пользователей к прочтению отзыва и написанию собственного отзыва [1]. Таким образом, отзывы могут размещаться экспоненциально в зависимости от количества читающих. Понимание поведение пользователей в сети по данным ХuX. [14] позволяет компаниям разрабатывать системы анализа и использовать положительный эффект сарафанного радио.

Рассмотрим некоторые факты об отзывах в интернете. Статистика говорит о том, что доля 85\% пользователей интернет-магазинов ориентируются на мнения предшествующих потребителей и это является основным фактором выбора [5]; 91\% покупателей читают отзывы в интернете; 90\% покупателей читают отзывы перед посещением магазина; 89\% опрошенных делают покупку в течение недели после прочтения отзывов (возможно данный аспект сопряжен с временем, отведенным на принятие решение о покупке и будущие расходы сопряжены с разными временными рамками на обдумывание. Например, время на решение для приобретения одежды будет отличаться от времени на решение о приобретении автомобиля и т.п.); 88\% покупателей относят отзывы к персональным рекомендациям; 31\% потенциальных покупателей готовы приобрести продукт / услугу, который имеет позитивные отзывы [10]; у 68\% опрошенных положительные отзывы повышают лояльность к бизнесу [4]. В целом статистика склоняет потенциального покупателя стать реальным покупателем при наличии положительных отзывов и наличии возможностей. Дополнительной возможностью также выступает кредитование, которое снижает чувствительность к цене товара/услуги. Как отмечено в работе Е.А. Тараненко [8], перед приобретением услуги/товара большинство потенциальных потребителей изучают отзывы в интернете об объекте интереса. Из этого следует, что на выбор потребителя влияют отзывы/комментарии других потребителей, уже столкнувшихся с объектом, после взаимодействия с которым происходит рефлексия, воплощаемая в отзыве. Соответственно осознание последовательности «покупка - опыт - рефлексия» помогает организациям улучшать свой сер- вис и продвигать товары/услуги на рынке. Таким образом, задача заключается в оперативном реагировании на негатив пользователей для последующего устранения их причин возникновения, а также налаживание коммуникации с пользователями/потребителями товаров/услуг [6].

Далее рассмотрим сущность негативных отзывов. В одном пункте исследования [4] утверждается, что пользователи в первую очередь уделяют свое внимание негативным и нейтральным отзывам пользователей сети. Соответственно, по остаточному принципу затем внимание падает на позитивные отзывы с благодарностями. С.В.Шиловский рассматривает одну из основных функций негативных отзывов, которая заключается в формировании доверия к источнику на основе его пройденного опыта, который может быть, как позитивным, так и негативным по объективным и субъективным причинам. Наличие только позитивных отзывов может свидетельствовать о работе модератора или редактора ресурса. [10] Негативное «сарафанное радио» оказывает большее влияние на поведение потребителей, чем позитивное «сарафанное радио». [11] Положительные оценки отзывов уменьшают количество комментариев к этим отзывам, а отрицательные оценки увеличивают количество комментариев [14]. «Неудовлетворенность» клиента определяется составом «противоречия» и «жалобы» [13]. Негативные отзывы в Интернете и ответы руководства оказывают решающее влияние на отношение и поведение потенциальных клиентов, которые читают информацию из отзывов и ответов и получают представление о продуктах и услугах продавца для принятия решения о покупке в Интернете [12]. Таким образом, задача отзывов заключается в формировании знаний у потенциального покупателя в условиях неопределенности информации или ее неоднозначности.

\section{Методы исследования}

В качестве данных для эмпирической части послужили отзывы пользователей с сайта banki. ru о Сбербанке в количестве $(\mathrm{N}=82051)$. Отзывы представляют собой заголовок отзыва, тело отзыва, оценка, поставленная пользователем, количество просмотров и другие атрибуты. Наиболее ценными атрибутами в этом исследовании выступают количество просмотров (“views”) и оценки отзывов. Как утверждалось выше, негативные отзывы больше привлекают внимание 
пользователей.

Как мы можем заметить на рис. 1 визуально количество отзывов с оценкой «1» больше всего (не считая отзывов без оценки).

Согласно Е.Н. Тулуповой и Е.В.Головиной [9], отзывы можно классифицировать на совет, предостережение, благодарность. Они выделяют также положительные, отрицательные и смешанные отзывы. Отзывы с оценкой три балла (по 5-и балльной системе) относятся к смешанным. 4 и 5-и балльные отзывы можно отнести к положительным, а 1 и 2-х балльные к отрицательным (негативным) отзывам.

По распределению количества просмотров отзывов (рис. 2) наблюдаем, что отзывы с оценкой «3» наиболее популярны среди посетителей раздела Сбербанк (Сбер) на сайте Banki.ru

Исследовательский интерес представляют отзывы, а именно их количество просмотров и как они соотносятся с оценками, которые ставят пользователи при размещении отзывов о банке. С целью проверки гипотезы о том, что негативные отзывы чаще читаются (или позитивные читаются реже), нами были проанализированы показатели “views” и «оценка». Научная новизна заключается в обосновании (подтверждении или отклонении) гипотезы статистическими методами.

Средние значения показателя “views” демонстрируют, что в целом реже всех остальных читаются отзывы с оценкой «5», а чаще остальных читаются отзывы с оценкой «3», а также отзывы без оценки (таблица 1).

Для поиска взаимозависимости между показателями «views» и «оценка» также был использован метод корреляционного анализа методом Пирсона.

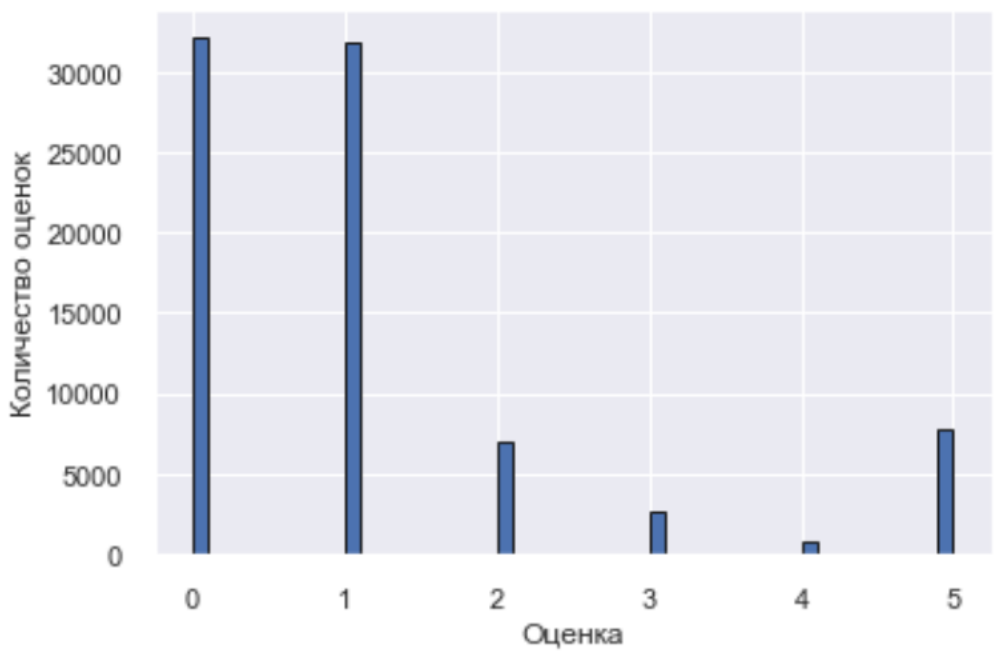

Рисунок 1. Распределение количества оценок

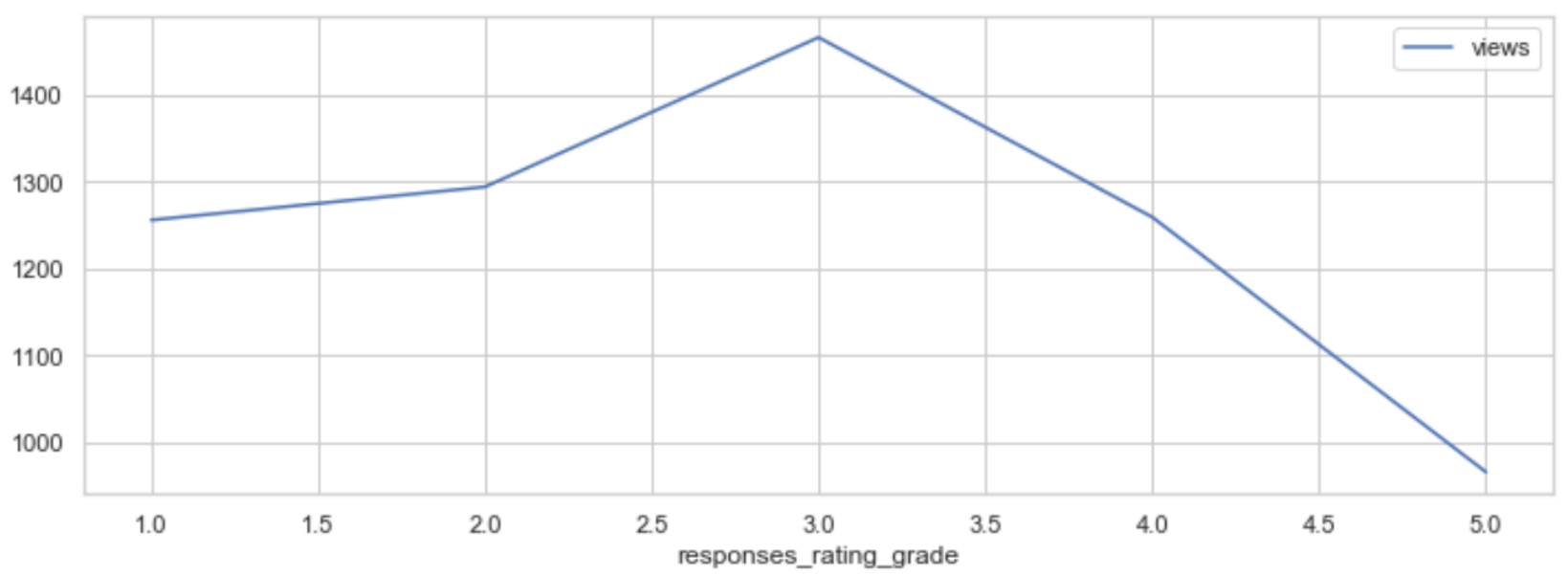

Рисунок 2. Распределение количества просмотров отзывов в зависимости от оценок 

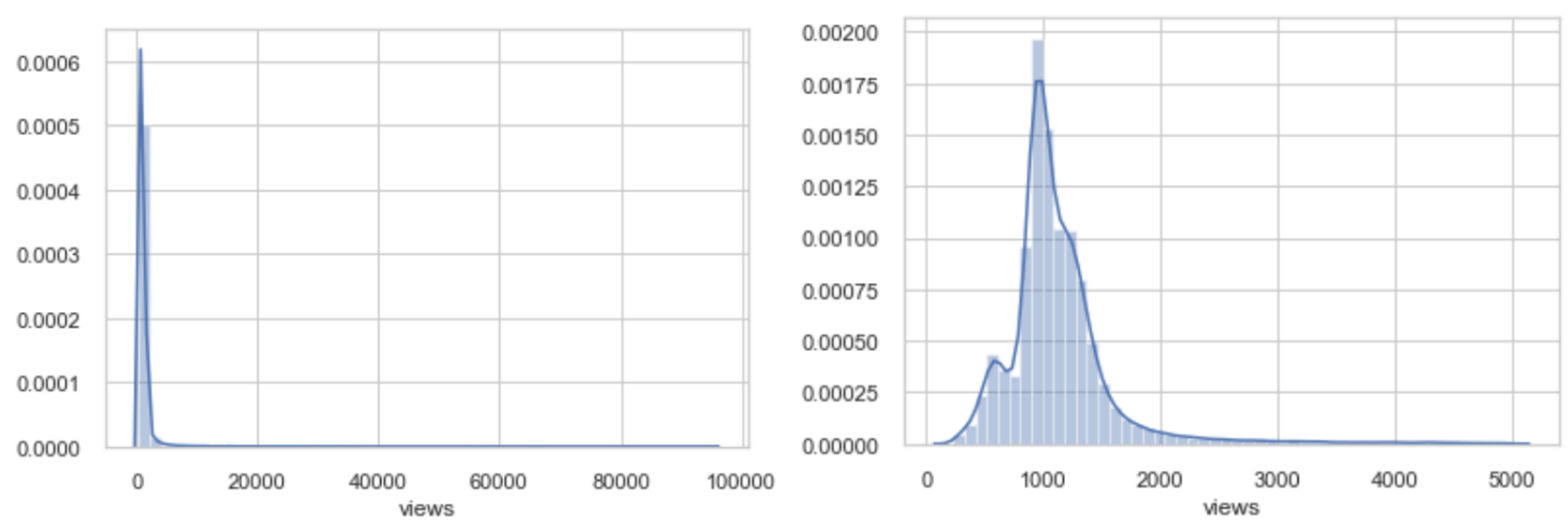

Рисунок 3. Распределение количества просмотров по отзывам (слева), распределение количества просмотров по отзывам с ограничим 5000 (справа)

Таблица 1. Статистика по просмотрам

\begin{tabular}{|c|c|c|c|}
\hline Оценка & Среднее значение & $\mathrm{N}$ & Стандартная отклонения \\
\hline 1,00 & 1255,97 & 31855 & 1292,261 \\
\hline 2,00 & 1294,25 & 6977 & 1413,667 \\
\hline 3,00 & 1465,58 & 2582 & 3373,349 \\
\hline 4,00 & 1258,99 & 700 & 1630,901 \\
\hline 5,00 & 966,38 & 7731 & 494,800 \\
\hline Нет оценки & 1356,05 & 32206 & 2215,427 \\
\hline Всего & 1277,84 & 82051 & 1777,985 \\
\hline
\end{tabular}

\section{Результаты исследования}

Поскольку отзывы с оценкой «5» просматриваются значительно реже остальных, на первом этапе данные отзывы были исключены из анализа. Результаты анализа показали, что между числом просмотров отзывов с оценками от 1 до 4, а также отзывами без оценки, не существует значимой корреляции ( $\left.\mathrm{r}=0,025^{* *}\right)$ Пирсона, таблица 2.

Таким образом, при исключении из массива данных отзывов с оценкой «5» справедлив следующий вывод: частота просмотров отзывов не зависит от их оценки.

На следующем этапе отзывы с оценкой «5» были включены в анализ. Результаты анализа показали, что между числом просмотров отзывов с оценками существует значимая, но крайне слабая корреляции $(\mathrm{r}=-0,061 *$ * значимость на уровне 0,01$)$, таблица 3.

Из таблицы 3 можно сделать вывод о том, что частота просмотров отзывов не зависит от их оценки или зависит очень слабо.

\section{Заключение}

Сопоставляя то, что частота просмотров отзывов не зависит от их оценки или зависит очень слабо, справедливо сделать следующее заключение: между оценкой, указанной в отзыве и частотой просмотров данного отзыва не существует статистически значимой зависимости, за исключением оценки «5» (наличие такой оценки снижает популярность отзыва). Соответственно, результаты исследования частично подтверждают гипотезу, выдвинутую зарубежными учеными (рассматривались во Введении настоящей статьи) о том, что положительные отзывы просматриваются по остаточному принципу. Частичность подтвержденной гипотезы означает то, что к положительным отзывам мы отнесли отзывы с оценкой «4» и «5», а как мы видим из результатов исследования, только отзывы с оценкой «5» отличаются в меньшую сторону от всех остальных отзывов.

\section{Благодарности}

Выражаем благодарность сайту Banki.ru за возможность анализировать отзывы отечественных банков. Исследование выполнено при финансовой поддержке РФФИ в рамках научного проекта № 20-310-70042. 
Таблица 2. Корреляции между оценками и количеством просмотров отзывов с оценками от 1 до 4, а также отзывами без оценки

\begin{tabular}{|c|c|c|c|}
\hline & & $\begin{array}{l}\text { Количество } \\
\text { просмотров }\end{array}$ & Оценка \\
\hline \multirow{3}{*}{ Количество просмотров } & Корреляция Пирсона & 1 & $0,025^{* * *}$ \\
\hline & Знач. (двухсторонняя) & & 0,000 \\
\hline & $\mathrm{N}$ & 42114 & 42114 \\
\hline \multirow{3}{*}{ Оценка } & Корреляция Пирсона & $0,025 * *$ & 1 \\
\hline & Знач. (двухсторонняя) & 0,000 & \\
\hline & $\mathrm{N}$ & 42114 & 82051 \\
\hline
\end{tabular}

Таблица 3. Корреляции между оценками и количествами просмотров отзывов с оценками от 1 до 5, а также отзывами без оценки

\begin{tabular}{|c|c|c|c|}
\hline & & $\begin{array}{l}\text { Количество } \\
\text { просмотров }\end{array}$ & Оценка \\
\hline \multirow{3}{*}{ Количество просмотров } & Корреляция Пирсона & 1 & $-0,061^{* *}$ \\
\hline & Знач. (двухсторонняя) & & 0,000 \\
\hline & $\mathrm{N}$ & 49845 & 49845 \\
\hline \multirow{3}{*}{ Оценка } & Корреляция Пирсона & $-0,061 * *$ & 1 \\
\hline & Знач. (двухсторонняя) & 0,000 & \\
\hline & $\mathrm{N}$ & 49845 & 82051 \\
\hline
\end{tabular}

\section{Библиографический список}

1. Ахметова А.Р. Топоним «Уфа» в креолизованных интернет-отзывах // Вестник ЧелГУ. 2020. № 1 (435). - с. 15-20.

2. Басовская Е.Н. Интернет-отзывы о питании: речевое воплощение современного российского «потребительского канона» // Общество. Коммуникация. Образование. 2020. № 2. - с. 78-86.

3. Былина Е.Э. К проблеме речеактовой отнесенности перформативного высказывания “I RECOMMEND” B интернет-отзыве // Преподаватель ХХІ век. 2020. № 3-2. - с. 391-405.

4. Зубков С.А., Панов А.И. Технологии защиты репутации бизнеса в цифровой экономике // Социальногуманитарные знания. 2020. № 5. - с. 295-309.

5. Климкина А.Г. Инструменты продвижения продукции: маркетинг из уст в уста // Актуальные проблемы авиации и космонавтики. 2019. № 2. С.809-811.

6. Максимова Л. М. Использование инструментов интернет-мониторинга для активизации процесса развития въездного туризма в РФ // Современные проблемы сервиса и туризма. 2011. № 3. - с. 43-48.

7. Погорелова И. В. Лингвосемиотический аспект интернет-отзыва // Филологические науки. Вопросы теории и практики. 2017. № 10-3 (76). - с. 149-152.

8. Тараненко E.А. Роль цифровой среды при определении качества сервиса в компаниях // Вестник ассоциации вузов туризма и сервиса. 2020. № 2-1. - с. 209-217.

9. Тулупова Е.Н., Головина Е.В. Лексико-стилистические особенности интернет-отзыва туриста // Филологические науки. Вопросы теории и практики. 2019. № 5. - с. 257-261.

10. Шиловский С. В. Влияние отзывов на вступление покупателей в бренд» сообщество розничной сети в социальной сети Facebook // Практический маркетинг. 2020. № 1 (275). - c. 18-22.

11. Craciun G., Moore K. Credibility of negative online product reviews: Reviewer gender, reputation and emotion effects //Computers in Human Behavior. - 2019. - T. 97. - C. 104-115.

12. Le L.H., Ha Q.A. Effects of negative reviews and managerial responses on consumer attitude and subsequent purchase behavior: An experimental design //Computers in Human Behavior. - 2021. - C. 106912.

13. Park $S$. et al. Customer sentiment analysis with more sensibility //Engineering Applications of Artificial Intelligence. - 2021. - T. 104. - C. 104356.

14. $и$ X. Closed-form evaluations and open-ended comment options: How do they affect customer online review behavior and reflect satisfaction with hotels? //Decision Support Systems. - 2021. - T. 145. - C. 113525. 